\title{
Prevention of Diabetes in BB/Wor Rats by Intrathymic Islet Injection
}

Steven B. Koevary and Maureen Blomberg

Department of Cell Biology, University of Massachusetts Medical School, Worcester, Massachusetts 01655

\begin{abstract}
The objective of this study was to determine whether the intrathymic injection of islets can prevent the development of diabetes in BB/Wor rats. Evidence suggests that a failure to induce islet thymic tolerance may be an etiological factor in the development of the disease. It was theorized that the introduction of islets into the thymus might directly induce islet tolerance and thus prevent disease. Islets from diabetes-resistant $\mathrm{BB} /$ Wor rats were injected into the thymuses of 23 young diabetes-prone BB/Wor rats; 25 sham-operated animals served as controls. Results showed that 22 of the 25 control rats became diabetic while only 8 of the 23 experimental rats became diabetic $(P<0.0002)$. The specific lysis of islet cells by spleen cells from nondiabetic experimental and control rats was comparable and less than the lysis induced by spleen cells from diabetic rats. These data demonstrate that the intrathymic injection of islets into diabetes-prone BB/Wor rats is an effective method for preventing the development of autoimmune type I diabetes. (J. Clin. Invest. 1992. 89:512-516.) Key words: natural killer cells ${ }^{51} \mathrm{Cr}$ release assay $\bullet$ insulin • YAC-1 cells • tolerance
\end{abstract}

\section{Introduction}

The BB/Wor rat spontaneously develops a diabetic syndrome similar to that of type I diabetic humans (1-3). These animals are ketosis prone and require insulin for survival. Though they are lymphopenic, cell-mediated immune processes have been implicated in the destruction of their islet cells, specifically those involving natural killer cells and T lymphocytes (4-7). In support of a role for $\mathrm{T}$ lymphocytes, thymectomy has been shown to prevent diabetes in $\mathrm{BB} /$ Wor rats (8).

Prevention of BB/Wor rat diabetes by thymectomy focused attention on the role of the thymus in the etiology of the disease. Data suggested that the thymus of diabetes-prone (DP) ${ }^{1}$ rats was defective $(9,10)$. Georgiou et al. (11) demonstrated that DP thymuses harbored defective macrophage-like antigen presenting cells (APCs) which were responsible for the activation of effector lymphocytes capable of destroying islet cells. Normally, thymic APCs are thought to play an important role in the generation of self tolerance (12). Since it appears that the

Address correspondence to Steven B. Koevary, Ph.D., Department of Cell Biology, University of Massachusetts Medical School, Worcester, MA 01655.

Received for publication 10 June 1991 and in revised form 22 July 1991.

1. Abbreviations used in this paper: APCs, antigen-presenting cells; DP, diabetes prone; DR, diabetes resistant.

J. Clin. Invest.

(c) The American Society for Clinical Investigation, Inc.

0021-9738/92/02/0512/05 $\$ 2.00$

Volume 89, February 1992, 512-516 development of diabetes in the BB/Wor rat may be due to an abnormal bone marrow-derived thymic APC, it was assumed that some defect in self-tolerance induction may be involved in disease development.

The objective of this study was to determine whether bolstering immunological tolerance to islet antigens can prevent the development of autoimmune diabetes in the rat. Injection of islets intrathymically might be one mechanism by which the activity of thymic APCs, vis-à-vis their role in establishing islet tolerance, could be enhanced. Ihm et al. (13) suggested that islets from rats of the age at which self tolerance is normally induced, i.e., neonates, lacked certain antigenic determinants, which could also explain the lack of islet tolerance in adult $\mathrm{BB} /$ Wor rats. Intrathymic injection of adult islets containing these antigens could help to reestablish islet tolerance. An important precedent for this study comes from the work of Posselt et al. (14), who successfully induced donor-specific unresponsiveness by transplanting islets intrathymically into two-month old, streptozotocin-induced diabetic allogeneic recipients.

\section{Methods}

Animals. BB/Wor rats were obtained from the University of Massachusetts breeding facility. 48 DP rats were used in this study. In addition, diabetes-resistant (DR) rats, used as a source of islet cells, and a small number of acutely diabetic BB/Wor rats (within five days of onset) were also used. Diabetes develops in DP animals at a mean $( \pm S E)$ age of $78.4 \pm 0.5 \mathrm{~d}$; the frequency of disease is between 80 and $90 \%$ (15). All DP rats used in this study were monitored for the presence of urine glucose starting at 50 days of age, using Testape (Eli Lilly \& Co., Indianapolis, IN).

Intrathymic injection of islets. Islets were isolated from 3-mo old DR rats as previously described (5). Before injection, the islets were irradiated with 1,800 rads (see Discussion). The cells were then washed twice and resuspended in serum-free RPMI medium in a siliconized tube. The yield from one to two rats (300-600 islets) was injected into each recipient thymus in a volume of $0.1 \mathrm{ml}$. Under ketamine/ropum anesthesia $(0.1 \mathrm{ml} / 100 \mathrm{~g}$ body $\mathrm{wt})$, the lower ventral neck and suprasternal regions of recipient rats were exposed. The superficial muscles as well as the upper few millimeters of the sternum were cut through, exposing the thymus. The islets were injected into the thymus using a 1 -cc syringe with a $27 \mathrm{G}$ needle. The wound was sealed using surgical staples. 23 randomized DP recipients (mean \pm SE age was $32 \pm 0.3 \mathrm{~d}$ ) were injected with DR islets, while 25 age matched, randomized DP rats were sham operated and had their thymuses injected with media alone.

The pancreatic and intrathymic islets of all nondiabetic rats remaining at the end of the study ( 150 days of age) were fixed in Bouin's solution, postfixed in $10 \%$ formalin, and embedded in paraffin. 4- $\mu \mathrm{m}$ sections were cut (at three different levels in the thymuses) and stained with hematoxylin and eosin, while adjacent sections were immunocytochemically stained for insulin and counterstained with hematoxylin.

Islet cell cytotoxicity assay. Spleen cells from nondiabetic DP rats remaining at the end of this study were examined for their ability to lyse DR rat islet target cells. Spleen cells from acutely diabetic and DR rats served as positive and negative controls, respectively. The assay involved the use of ${ }^{51} \mathrm{Cr}$ and has been described in detail elsewhere (5). The media used was RPMI supplemented with $10 \%$ heat inactivated 
fetal calf serum (Gibco Laboratories, Grand Island, NY), $5 \mathrm{mM}$ glutamine, $5 \times 10^{-5} \mathrm{M} \beta$-mercaptoethanol, $100 \mathrm{U} / \mathrm{ml}$ penicillin, and 100 $\mu \mathrm{g} / \mathrm{ml}$ streptomycin.

Spleen cells $\left(10^{7} / \mathrm{ml}\right)$ were pipetted in quadruplicate into round bottomed wells in a 96-well plate (Costar Corp., Cambridge, MA) in a volume of $100 \mu \mathrm{l}$. Target islet cells were isolated from DR rats and dissociated as previously described (5). Islet cells $(200,000$ cells $/ \mathrm{ml})$ which had previously been labelled with ${ }^{51} \mathrm{Cr}\left(200 \mu \mathrm{l}\right.$ of ${ }^{51} \mathrm{Cr}$-as sodium chromate for $1 \mathrm{~h}$ at $37^{\circ} \mathrm{C}$, followed by three washes; sp act 400-1,200 $\mathrm{Ci} / \mathrm{g}$; New England Nuclear, Boston, MA) were then added into the wells in a volume of $100 \mu \mathrm{l}(20,000$ target cells/well; effector:target ratio of $50: 1)$. The plates were centrifuged for $1 \mathrm{~min}$ at $700 \mathrm{rpm}$ and incubated for $16 \mathrm{~h}$ in $5 \% \mathrm{CO}_{2}$ in air at $37^{\circ} \mathrm{C}$. Supernatants $(100 \mu \mathrm{l})$ were then removed from each well and counted in a gamma counter (Packard Instrument Co., Inc., Meriden, CT). The percent specific lysis was calculated using the following formula:

$\%$ Specific lysis

$=\frac{\text { Experimental }(\mathrm{cpm})-\text { Spontaneous release }(\mathrm{cpm})}{\text { Total }(\mathrm{cpm})-\text { Spontaneous release }(\mathrm{cpm})} \times 100$.

Total counts were determined at the beginning of the assay by counting $0.1-\mathrm{ml}$ aliquots of ${ }^{51} \mathrm{Cr}$-labelled target cells. Spontaneous release of ${ }^{51} \mathrm{Cr}$ from target cells incubated in the absence of spleen cells was also determined. In addition to islet cell targets, YAC-1 target cells were also used in this assay. YAC-1 cells are natural killer-sensitive mouse leukemia virus-induced, T lymphoma cells (16). These cells were labelled and otherwise handled in the same way as islet cell targets.

$F A C S^{\oplus}$ analysis of lymphocyte subsets. Lymphocyte subsets in the spleens of nondiabetic experimental and control DP rats were analyzed on the FACS ${ }^{\oplus}$. Double label analyses were performed using monoclonal antibodies OX19 and OX8. OX19 reacts with all T cells. Classical cytotoxic/suppressor T cells are contained in the OX8+/OX19+ lymphocyte subset while natural killer cells are contained in the OX8+/ OX19- lymphocyte subset. $5 \times 10^{6}$ spleen cells were incubated with $200 \mu \mathrm{l}$ of mouse monoclonal OX8 (30 $\mu \mathrm{g} / \mathrm{ml}$; Bioproducts for Science, Inc., Indianapolis, IN) for $30 \mathrm{~min}$, washed twice, and incubated with $200 \mu \mathrm{l}$ of fluorescein-conjugated goat anti-mouse IgG $(30 \mu \mathrm{g} / \mathrm{ml}$ : Organon Teknika/Cappel, Rockville, MD) for $30 \mathrm{~min}$. This secondary antibody does not cross-react with rat IgG. The cells were washed twice, incubated with $200 \mu \mathrm{l}$ of mouse IgG $(200 \mu \mathrm{g} / \mathrm{ml}$; Organon Teknika/ Cappel) to block any remaining active sites on the secondary antibody, washed twice, and incubated with $200 \mu \mathrm{l}$ of OX19-biotin $(30 \mu \mathrm{g} / \mathrm{ml}$ : Bioproducts for Science; biotinylation performed by Molecular Probes, Eugene, OR) for $30 \mathrm{~min}$. After OX19-biotin incubation, the cells were washed twice and incubated with $100 \mu \mathrm{l}$ of streptavidin-R-phycoerythrin conjugate ( $20 \mu \mathrm{g} / \mathrm{ml}$; Molecular Probes) for $30 \mathrm{~min}$. All incubations and washes were performed in PBS supplemented with $0.5 \%$ BSA (Sigma Chemical Co., St. Louis, MO) at $4^{\circ} \mathrm{C}$. Background fluorescence was determined by controls in which normal mouse IgG was substituted for one of the primary antibodies (OX8 or OX19). After this double labelling procedure, cells were fixed in $4 \%$ paraformaldehyde for $7 \mathrm{~min}$ at $4^{\circ} \mathrm{C}$, washed twice, and resuspended in MEM media supplemented with $10 \%$ heat inactivated fetal calf serum. Fixed cells were analyzed ( $\geq 25,000$ cells/sample) using a FACSStar Plus ${ }^{\oplus}$ (Becton Dickinson \& Co., Mountain View, CA).

Statistics. The Student's $t$ test was used to determine significance levels for the cytotoxicity and FACS ${ }^{\oplus}$ data. The effects of intrathymic islet injections on the incidence of diabetes was evaluated using Fisher's exact test (17).

\section{Results}

Effects of intrathymic islet injection on diabetes incidence The intrathymic injection of islets into DP rats significantly reduced $(P<0.0002)$ their incidence of diabetes. These results are shown in Table I. 88\% (22 of 25) of control, sham-operated
Table I. Effects of Intrathymic Islet Injections on the Development of Diabetes in the BB/Wor Rat

\begin{tabular}{lccc}
\hline \multicolumn{1}{c}{ Treatment } & $n$ & Number diabetic & Percent diabetic \\
\hline Sham operated & 25 & 22 & 88 \\
Intrathymic islets & 23 & $8^{\ddagger}$ & 35 \\
\hline
\end{tabular}

* Thymuses injected with vehicle. ${ }^{\ddagger}$ Significantly fewer than sham operated, $P<0.0002$.

rats became diabetic by 150 days of age, while only $35 \%$ ( 8 of 23) experimental rats developed disease. The age of onset of diabetes in animals that did become diabetic was similar in both groups (mean $\pm \mathrm{SE}$ was $83.6 \pm 4.5$ for the controls and 78.4 \pm 5.2 for the experimentals).

Morphological analysis of the thymuses of nondiabetic experimental animals revealed the presence of islet tissue containing well granulated beta cells (Fig. 1), though fewer islets were found than expected, considering the numbers injected. When present, intact islets were generally observed within connective tissue septa; distorted islets and large and small groups of individual islet cells were present within the thymic parenchyma. Analysis of 5 of the 8 thymuses of experimental animals that became diabetic revealed a pattern of islet distribution similar to that seen in protected animals. Examination of the pancreata of nondiabetic animals remaining at the end of the study revealed an absence of autoimmune insulitis in both experimental and control groups. However, three experimental and two control pancreata displayed periductular and perivascular inflammation.

\section{${ }^{51}$ Cr-release assay}

Spleen cells from a number of nondiabetic experimental ( $n$ $=10)$ and control $(n=3)$ DP rats were analyzed for their ability to lyse islet and YAC-1 cell targets. Results are shown in Table II. There were no significant differences between the level of killing of islet or YAC-1 cells between experimental and control rats. Lysis of islet cells by spleen cells from both experimental nondiabetic (mean \pm SE was $15.9 \pm 1.6$ ) and control nondiabetic $(16.4 \pm 1.1)$ animals was significantly lower $(P<0.001)$ than lysis by spleen cells from diabetic rats $(26.4 \pm 1.4 ; n=4)$. YAC-1 lysis by spleen cells from experimental nondiabetic $(60 \pm 1.6)$ and control $(54.5 \pm 2.5)$ animals were insignificantly different from lysis by spleen cells from diabetic rats $(59.4 \pm 1.5$; $n=4)$.

\section{$F A C S^{\otimes}$}

The mean \pm SE concentrations of OX19+ and OX8+/OX19cells were $11.0 \pm 0.5 \%$ and $18.0 \pm 1.0 \%$, respectively, in the experimental group $(n=10)$ and $9.4 \pm 0.7 \%$ and $14.5 \pm 3.0 \%$, respectively, in the control group $(n=3)$ (not significant). The mean \pm SE concentrations of $\mathrm{OX} 8+/ \mathrm{OX} 19+$ cells were $1.2 \pm 0.1$ in the experimental group and $0.9 \pm 0.1 \%$ in the control group ( $P<0.02$ compared to experimental group).

\section{Discussion}

The objective of this study was to determine whether the intrathymic injection of islets into DP rats can prevent the development of disease in the $\mathrm{BB} /$ Wor rat. Our results suggest that 

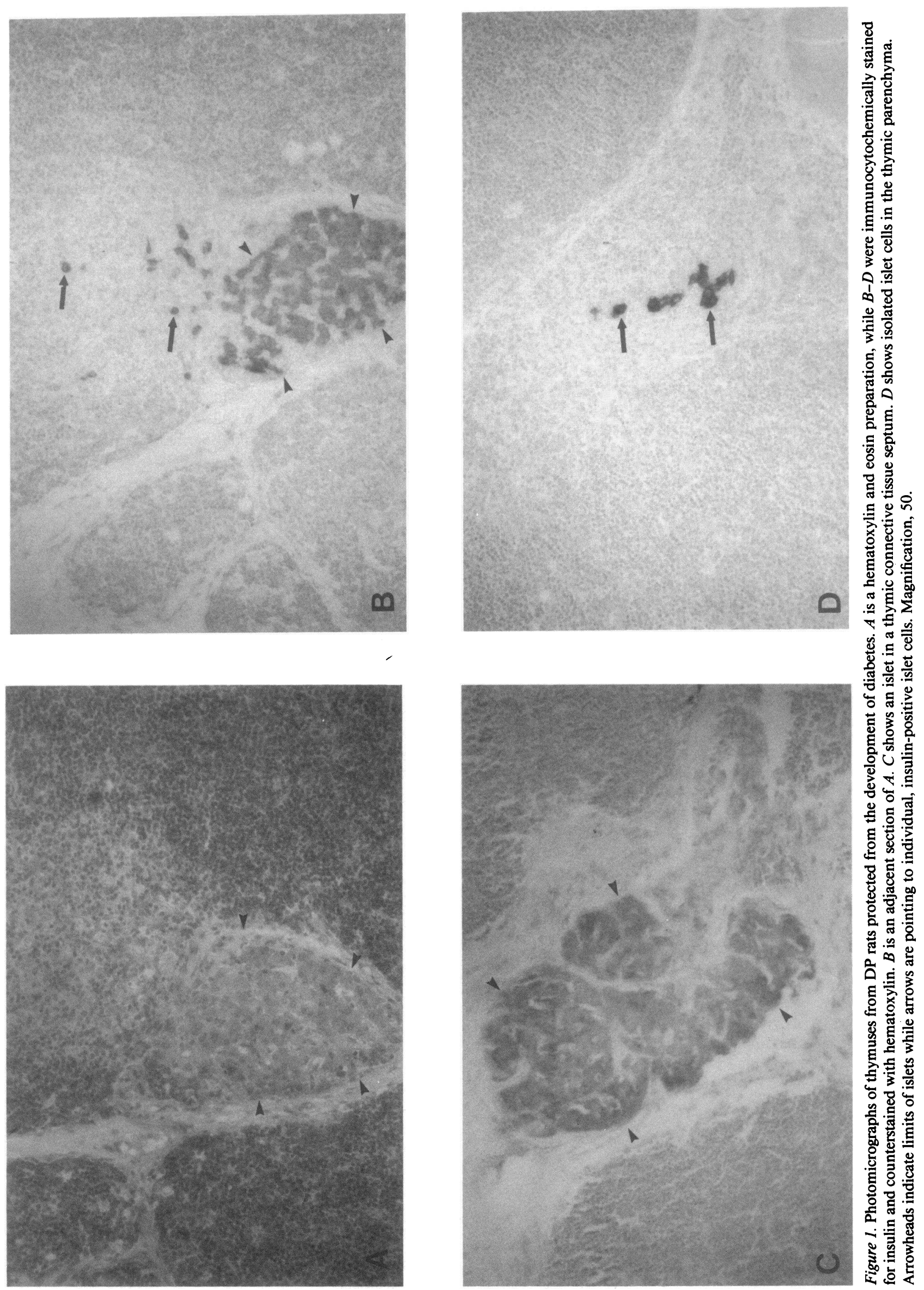
Table II. ${ }^{51} \mathrm{Cr}$ Release from DR Islets and YAC-1 Cells Incubated with Spleen Cells from Nondiabetic Experimental and Control Rats

\begin{tabular}{lll}
\hline Target & \multicolumn{1}{c}{ Spleen cell donor } & Percent specific lysis $($ mean \pm SE) \\
\hline \multirow{2}{*}{ Islet } & Experimental nondiabetics & $15.9 \pm 1.6$ \\
& Control nondiabetics & $16.4 \pm 1.1$ \\
YAC-1 & Experimental nondiabetics & $60.0 \pm 1.6$ \\
& Control nondiabetics & $54.5 \pm 2.5$
\end{tabular}

All experimental and control values within a target group were statistically insignificantly different from each other. Spleen cells from acutely diabetic BB/Wor rats and DR rats served as positive and negative controls for this assay. Lysis of islet and YAC-1 cells by acutely diabetic spleen cells was $26.4 \pm 1.4 \%$ and $59.4 \pm 1.5 \%$, respectively, while DR lysis was $6.5 \%$ and $31.5 \%$, respectively.

autoimmune type I diabetes can in fact be prevented using this methodology.

Morphological examination of the thymuses of protected animals revealed relatively few islets, considering the number injected, in spite of the fact that three thymic levels were examined. Intact islets were observed only within thymic connective tissue septa. Islet cells that were localized within the lymphocyte parenchyma of the thymus were present as small, isolated clusters of few cells and not as intact islets. Most of these cells seemed to be present in or near the thymic medulla. What might be speculated from these observations is that islets do not survive well in the thymic cortex, perhaps because thymic macrophages and lymphocytes have eliminated them in the process of presenting them to maturing $T$ cells. A time course study of the disposition of intrathymic islets should help to clarify these findings. It is not immediately clear why all of the experimental animals were not protected from the development of diabetes, since they all appeared to have the same pattern of islet distribution within their thymuses. A quantitative time course analysis of the fate of intrathymic islets should also help to answer this question.

Recall that the islets were first irradiated before their intrathymic injection. This was done in an attempt to interfere with their ability to release insulin in response to glucose. Gotfredsen et al. (18) and Like (19) suggested that insulin injections could prevent the development of BB rat diabetes by diminishing the activity and size, and consequently the immunogenicity, of their islets. Though the possibility seemed remote that the levels of insulin released from intrathymic islets could reach high enough levels to reduce the activity of the pancreatic islets, we thought we would try to eliminate this possibility altogether by the simple method of irradiation. Our data (not shown) suggested that irradiation had no effect on the inhibition of islet insulin secretion. It should be emphasized, however, that the possibility that insulin, released from intrathymic islets, could play a role in diabetes prevention is considered very remote. Data from Hegre et al. showed that transplantation of islets into DP rats before 60 days of age did not appear to affect their incidence of diabetes (20). In addition, subjectively, the size of the pancreatic islets of protected animals appeared similar to the size of the islets in the pancreata of control, nondiabetic rats; thus a "shutting down" of the pancreatic islets did not seem to be occurring. Successful protection from disease by injecting fixed islets intrathymically would unequivocally lay this question to rest.

Experimental nondiabetic rats remaining at the end of this study exhibited a similar capacity to lyse islet target cells in vitro compared to control rats. This lysis was less than that exhibited by spleen cells from acutely diabetic rats but greater than the lysis by DR spleen cells. It may be theorized that the intrathymic injection of islets in DP rats prevented the augmentation of splenic antiislet immunoreactivity to that seen in diabetic animals and thus prevented the development of disease. Spleen cell lysis of YAC-1 cells was similar in experimental and control groups and comparable to that exhibited by spleen cells from diabetic rats. The fact that DP spleen cell lysis of YAC-1 cells was comparable to diabetic spleen cell lysis has been previously reported $(21,22)$.

The extremely slight, but statistically significant, increase in the number of OX8+/OX19+ cells is probably not biologically significant, though it is tempting to speculate that it represents an increase in the number of islet suppressor cells. Interestingly, Posselt et al. (14) similarly revealed no differences in lymphocyte populations between thymic islet allograft recipients and normal controls or hosts of long-standing intratesticular or renal subcapsular allografts. It is clear that changes in lymphocyte subsets do not necessarily correlate with changes in the disease state. Thus, Thomas et al. (23) failed to show changes in lymphocyte subsets in DR rats that developed diabetes after polyinosinic polycytidilic acid treatment, and Rossini et al. (24) showed no changes in lymphocyte subsets after total lymphoid irradiation in diabetes-protected animals. Changes in the activity of lymphocytes within a given subset may have accounted for these, and our present, findings.

Evidence suggests that a failure to induce islet tolerance may be an etiological factor in the development of diabetes. This evidence includes the data of Georgiou et al. (11), who showed that thymic APCs in DP rats may be defective in their ability to establish islet tolerance. In all likelihood, this lack of tolerance induction manifests itself by the absence of cells capable of suppressing islet effectors. Furthermore, the data of $\mathrm{Ihm}$ et al. (13) suggested that islets from rats of the age at which self tolerance is normally induced, i.e., neonates, lacked certain antigenic determinants, which could explain the lack of islet tolerance in adult DP rats. In support of Ihm's data, Buschard et al. (25) reported that diabetes in BB rats can be prevented by the neonatal stimulation of beta cells. This procedure was thought to induce or enhance antigen expression on the beta cells, which facilitated the immune system's ability to develop beta cell tolerance (26).

As mentioned earlier, Posselt et al. (14) were successful in inducing donor-specific unresponsiveness by transplanting islets intrathymically into two-month old streptozotocin-induced diabetic allogeneic recipients. Not only were the intrathymic islets not rejected, but once tolerance was achieved, islets transplanted to extrathymic sites were also protected. Our study is significant since it shows that not only rejection but specific autoimmune attack can be prevented by intrathymic islet injection. Recall that in a diabetic recipient of an identical twin's pancreatic graft, a specific autoimmune attack was responsible for the destruction of the beta cells in that graft soon after transplantation (27). While it is tempting to attribute the findings presented here to the induction of specific islet tolerance, such a conclusion awaits further experimentation. 


\section{Acknowledgments}

We thank Yu Jiang for her expert technical assistance.

This work was supported by a grant from the Juvenile Diabetes Foundation, International.

\section{References}

1. Nakhooda, A. F., A. A. Like, C. I. Chappel, F. T. Murray, and E. B. Marliss. 1977. The spontaneously diabetic Wistar rat. Metabolic and morphologic studies. Diabetes. 26:100-112.

2. Mordes, J. P., and A. A. Rossini. 1987. Keys to understanding autoimmune diabetes mellitus: the animal models of insulin dependent diabetes mellitus. Clin. Immunol. \& Allergy. 1:29-51.

3. Mordes, J. P., J. Desemone, and A. A. Rossini. 1987. The BB rat. Diabetes Metab. Rev. 3:725-750.

4. MacKay, P., J. Jacobson, and A. Rabinovitch. 1986. Spontaneous diabetes mellitus in the BB/W rat: evidence in vitro for natural killer cell lysis of islet cells. J. Clin. Invest. 77:916-924.

5. Koevary, S. B. 1990 . In vitro lysis of islet cells by lymphocytes in the spontaneously diabetic BB/Wor rat is not antibody mediated. Diabetes Res. Clin. Pract. 13:133-138.

6. Jacobson, J. D., J. F. Markmann, K. L. Brayman, C. F. Barker, and A. Naji. 1988. Prevention of recurrent autoimmune diabetes in BB rats by anti-asialoGM1 antibody. Diabetes. 37:838-841.

7. Like, A. A., C. A. Biron, E. J. Weringer, K. Byman, E. Sroczynski, and D. L. Guberski. 1986. Prevention of diabetes in BioBreeding/Worcester rats with monoclonal antibodies that recognize T lymphocytes or natural killer cells. $J$. Exp. Med. 164:1145-1159.

8. Like, A. A., E. Kislauskis, R. M. Williams, and A. A. Rossini. 1982. Neonatal thymectomy prevents spontaneous diabetes mellitus in the BB/W rat. Science (Wash. DC). 216:644-646.

9. Scott, J., D. C. Benjamin, J. C. Herr, and V. H. Engelhard. 1988. Sites of the defects leading to autoimmunity in the spontaneously diabetic BB rat. In Prediabetes. R. A. Camerini-Davalos and H. S. Cole, editors. Plenum Publishing Corp., NY., pp. 53-62.

10. Rozing, J., C. Coolen, F. J. Tielen, J. Weegenaar, H. J. Schuurman, D. L. Greiner, and A. A. Rossini. 1989. Defects in the thymic epithelial stroma of diabetes prone BB rats. Thymus. 14:125-135.

11. Georgiou, H. M., A. C. Lagarde, and D. Bellgrau. 1988. T cell dysfunction in the diabetes-prone BB rat: a role for thymic migrants that are not $T$ cell precursors. J. Exp. Med. 167:132-48.
12. Lo, D., and J. Sprent. 1986. Identity of cells that imprint H-2 restriction in the thymus. Nature (Lond.). 319:672-674.

13. Ihm, S. H., K. H. Lee, and J. W. Yoon. 1991. Studies on autoimmunity for initiation of $\beta$-cell destruction. VII. Evidence for antigenic changes on $\beta$-cells leading to autoimmune destruction of $\beta$-cells in BB rats. Diabetes. 40:269-274.

14. Posselt, A. M., C. F. Barker, J. E. Tomaszewski, J. F. Markmann, M. A. Choti, and A. Naji. 1990. Induction of donor-specific unresponsiveness by intrathymic islet transplantation. Science (Wash. DC). 249:1293-1295.

15. Guberski, D. L., L. Butler, and A. A. Like. 1990. Environmental viral agents influence spontaneous and RT6 depletion induced diabetes in the BB/Wor rat. Diabetes. 39(Suppl. 1):97a. (Abstr.)

16. Kiessling, R., E. Klein, and H. Wigzell. 1976. Natural killer cells in the mouse. I. Cytotoxic cells with specificity for mouse Moloney leukemia cells. Specificity and distribution according to genotype. Eur. J. Immunol. 5:112-116.

17. Siegel, S. 1956. Non-parametric Statistics for the Behavioral Sciences. McGraw-Hill, Inc., NY. pp. 96-104.

18. Gotfredsen, C. F., K. Buschard, and E. K. Frandsen. 1985. Reduction of diabetes incidence of BB Wistar rats by early prophylactic insulin treatment of diabetes prone animals. Diabetologia. 28:933-935.

19. Like, A. A. 1986. Insulin injections prevent diabetes in BB/Wor rats. Diabetes. 35(Suppl. 1):75a. (Abstr.)

20. Hegre, O. D., A. J. Enriquez, R. J. Ketchum, A. J. Weinhaus, and J. R. Serie. 1989. Islet transplantation in spontaneously diabetic BB/Wor rats. Diabetes. 38:1148-1154.

21. Nakamura, N., B. A. Woda, A. Tafuri, D. L. Greiner, C. W. Reynolds, J. Ortaldo, W. Chick, E. S. Handler, J. P. Mordes, and A. A. Rossini. 1990. Intrinsic cytotoxicity of natural killer cells to pancreatic islets in vitro. Diabetes. 39:836843.

22. Koevary, S. B. 1988. In vitro natural killer cell activity in the BB/Wor rat: effect of serum on lysis of beta cells. Diabetes Res. Clin. Pract. 8:77-84.

23. Thomas, V. A., B. A. Woda, E. S. Handler, D. L. Greiner, J. P. Mordes, and A. A. Rossini. 1991. Altered expression of diabetes in BB/Wor rats by exposure to viral pathogens. Diabetes. 40:255-258.

24. Rossini, A. A., S. Slavin, B. A. Woda, M. Geisberg, A. A. Like, and J. P. Mordes. 1984. Total lymphoid irradiation prevents diabetes mellitus in the BioBreeding/Worcester (BB/W) rat. Diabetes. 33:543-547.

25. Buschard, K., M. Jorgensen, K. Aaen, T. Bock, and K. Josefsen. 1990. Prevention of diabetes mellitus in BB rats by neonatal stimulation of B cells. Lancet. 335:134-135.

26. Aaen, K., J. Rygaard, K. Josefsen, H. Petersen, C. H. Brogren, T. Horn, and K. Buschard. 1990. Dependence of antigen expression on functional state of B cells. Diabetes. 39:697-701.

27. Sibley, D. K., D. E. R. Sutherland, F. Goetz, and A. F. Michael. 1985. Recurrent diabetes mellitus in the pancreas iso and allograft: a light and electron microscope and immuno-histochemical analysis. Lab. Invest. 52:773-782. 